\title{
IMPLEMENTASI GAME BAHASA MODEL UJI PENGETAHUAN UNTUK MENINGKATKAN PENGUASAAN KOSA KATA BAHASA ARAB
}

\author{
Wardani $^{1}$, Almanna Wassalwa ${ }^{2}$ \\ ${ }^{1,2}$ Universitas Ibrahimy Situbondo \\ 1'wardaniunibsalsaf@gmail.com, ${ }^{2}$ salwaelmanna90@gmail.com
}

\begin{abstract}
This research is to describe the implementation of the knowledge test language game model to improve the ability of Arabic vocabulary in the Arabic Language Development Institute (LPBA) in Salafiyah Syafi'iyah Islamic Boarding School Sukorejo Situbondo East Java, Academic Year 20142015. By using a qualitative approach to the type of case study research. The method of collection data technique uses the interviews, observation, and documentation. With data analysis namely data reduction, data description, and conclusions. Based on the results of the analysis, it can be concluded that: the implementation of the language game with the knowledge test model to improve the ability of Arabic vocabulary is sufficient and competent by providing direction and guidance, fostering learning motivation for members to reward outstanding members and all things that can support towards the smooth teaching and learning process. such as the use of audio-visual media so that effective and motivative learning is created; and factors that can influence improving Arabic vocabulary mastery in the Institute of Arabic Language Development (LPBA) Salafiyah Syafi'iyah Sukorejo Islamic Boarding School in Situbondo East Java is clarified into two types, namely: consists of internal factors, such as the ability to think and external factors such as the encouragement of parents and teachers.
\end{abstract}

Keywords: Language Game, the Knowledge Test Model, Arabic Vocabulary

\section{PENDAHULUAN}

Bahasa asing atau al-lughah alajnabiyyah dalam bahasa Arab dan foreign language dalam bahasa inggris secara umum adalah bahasa asing yang di gunakan oleh orang asing. ${ }^{1}$ Di Indonesia, selain bahasa Nasional dan bahasa Daerah, terdapat juga pemakaian bahasa asing tertentu seperti bahasa Arab, Inggris, Jerman dan Perancis. Bahasa Arab diakui sebagai bahasa yang pertama di dunia ini. Dan juga sebagai bahasa Agama diajarkan mulai dari tingkat ibtidak, mutawassit end anniha'i, sampai dengan tingkat tertentu di lembaga-lembaga Perguruan Tinggi Agama Islam (PTAI), dan

${ }^{1}$ Acep hermawan, Metodologi Pembelajaran Bahasa Arab, (Jogjakarta : DIVA Press (Anggota IKAPI),2012), hlm : 55 secara kurikuler bahasa Arab menduduki posisi sebagai mata pelajaran wajib. ${ }^{2}$

Bahasa memegang peranan penting dalam kehidupan manusia. hal ini harus disadari dan diperhatikan dengan baik oleh guru bahasa khususnya, maupun guru bidang studi pada umumnya. Kompetensi berbahasa merupakan aspek penting dalam belajar bahasa termasuk dalam belajar bahasa asing, khususnya bahasa Arab. Dalam mempelajari bahasa, ada empat kemahiran yang tidak dapat dipisahkan satu sama lain, yaitu: kemahiran mendengar, berbicara, mambaca dan menulis. Keempat kemahiran tersebut saling mendukung satu sama lain dalam mencapai kemampuan berbahasa seseorang, begitu juga kemahiran menulis. Menulis merupakan bentuk keterampilan berbahasa yang paling akhir dikuasai oleh pembelajar

${ }^{2}$ Azhar Arsyad, Bahasa Arab dan Metode Pengajarannya, (Yogyakarta: Pustaka Pelajar, cet.II, 2004), hlm. 156. 
bahasa setelah kemahiran mendengar, berbicara dan membaca. Keterampilan menulis merupakan keterampilan yang sangat dibutuhkan pada masa sekarang. Keterampilan ini menjadi salah satu cara untuk mengungkapkan pemikiran, perasaan, harapan, cita-cita, atau segala sesuatu yang dipikirakan dan dirasakan oleh manusia. ${ }^{3}$

Karena dengan berkembangnya zaman modernisasi sangatlah penting di adakan sebuah kursusan yang berbasis bahasa khususnya bahasa Arab yang selayaknya di dirikan di dalam pondok-pondok pesantren yang bisa membantu kemajuannya semua lembaga yang ada di dalamnya, oleh karena itu dengan terdorongnya hal tersebut maka di pondok yang tercinta ini di dirikanlah sebuah lembaga kursusan khususnya bahasa Arab yang di dirikan secara resmi dan di beri nama lembaga pengembangan bahasa Arab (LPBA) pondok pesantren Salafiyah Syafiiyah Sukorejo Situbondo Jawa Timur, yang sampai sekarang masih konsis dan sudah banyak perkembangannya baik dari kualitasnya maupun kuantitasnya, dan keseluhan dari anggota yang kursus itu dari berbagai macam tingkatan, dari tingkatan SMP,SMA/SMK dan PERGURUAN TINGGI, sehingga anggota yang memiliki pengalaman belajar bahasa Arab sangat sedikit kecuali yang sudah pernah berada di pondok pesantren di rumahnya sebelum mondok di pesantren yang tercinta ini. Hal ini tentu sangat berpengaruh terhadap kegiatan pembelajaran di lembaga pengembangan bahasa Arab (LPBA) tersebut. Dalam pembelajaran, banyak metode yang sudah aplikasikan salah satunya aadalah metode game bahasa uji pengetahuan, semua anggota khususnya yang sebelumnya tidak mempelajari bahasa Arab masih mengalami beberapa hambatan, antara lain anggota belum benar-benar menguasai kemahiran bahasa lainnya. Misalnya: anggota mengalami kesulitan dalam membaca tulisan Arab, hal itu akan berpengaruh terhadap kamahiran menulisnya. Sedangkan dalam kemahiran metode game bahasa uji pengetahuan sendiri, hambatan yang dihadapi adalah banyak anggota yang belum menguasai pembelajaran

${ }^{3}$ ibid . 123 bahasa Arab, dan belum dapat bisa mencernah apa yang telah di jelaskan dengan benar. Untuk mengatasi masalah tersebut guru bidang studi bahasa Arab di lembaga pengembangan bahasa Arab (LPBA) pondok pesantren Salafiyah Syafiiyah Sukorejo Situbondo Jawa Timur tersebut mengunakan berbagai metode salah satunya yaitu dengan cara tiap anggota satu persatu untuk maju kedepan untuk menuliskan kosa kata/mufrodat yang sudah ditentukan oleh guru tersebut. Terkadang guru juga menyuruh siswa untuk menyiapkan kertas kemudian guru tersebut memaparkan terhadap anggota.

Oleh karena itulah peneliti bermaksud melakukan penelitian terhadap metode yang di terapkan oleh guru tersebut, yang mana menurut Drs. H. Tayar yusuf dalam bukunya yang berjudul metodologi pengajaran agama dan bahasa Arab metode yang diterapkan di lembaga pengembangan bahasa Arab (LPBA) pondok pesantren Salafiyah Syafiiyah Sukorejo Situbondo Jawa Timur itu adalah metode game bahasa uji pengetahuan.

Adapun faktor yang terkait dengan pembelajaran metode game bahasa uji pengetahuan untuk meningkatkan kemampuan anggota antara lain adalah metode yang digunakan oleh guru. Penggunaan metode memiliki peran yang sangat penting dalam keberhasilan suatu proses pembelajaran. Metode merupakan satu rencana menyeluruh mengenai penyajian bahasa secara sistematis berdasarkan pendekatan yang ditentukan. ${ }^{4}$

Tidak semua metode dapat digunakan pada setiap materi pembelajaran. Oleh karena itu, seorang guru harus dapat memilih metode yang tepat dengan materi pembelajaran yang akan disampaikan. Adapun dalam pembelajaran metode game bahasa uji pengetahuan, salah satu metode yang dapat digunakan adalah metode game bahasa uji pengetahuan. Dalam metode game bahasa uji pengetahuan, anggota tidak hanya diajarkan untuk terampil menulis, akan tetapi juga dilatih untuk mengembangkan keterampilan mendengar, mengeja serta membaca tulisan

\footnotetext{
${ }^{4}$ Syamsuddin Asyrofi, et.al, Metodologi Pembelajaran Bahasa Arab, (Yogyakarta: Pokja Akademik, 2006),
} hlm. 82 . 
Arab. Dengan penggunaan metode game bahasa uji pengethuan ini, diharapkan dapat meningkatkan kemahiran game bahasa anggota.

Berdasarkan latar belakang masalah diatas dapat dirumuskan permasalahan sebagai berikut.

1. Bagaimana Implementasi game bahasa model uji pengetahuan untuk meningkatkan penguasaan kosa kata bahasa Arab di lembaga pengembangan bahasa Arab (LPBA) pondok pesantren Salafiyah Syafiiyah Sukorejo Situbondo tahun pelajaran 2014/2015?

2. Apakah faktor-faktor Pendukung dan penghambat game bahasa model uji pengatahuan untuk meningkatkan penguasaan kosa kata bahasa Arab di lembaga pengembangan bahasa Arab (LPBA) pondok pesantren Salafiyah Syafiiyah Sukorejo Situbondo JawaTimur tahun pelajaran 2014/2015?

\section{METODE PENELITIAN}

Penelitian ini menggunakan pendekatan kualitatif. Dengan teknik pengumpulan data terdriri dari observasi, wawancara, dan dokumentasi

\section{PEMBAHASAN}

Berdasarkan hasil interview yang telah dilakukan untuk memperkuat validitas data hasil observasi, maka dalam pembahasan temuan hasil analisis data, akan difokuskan pada 2 (dua) permasalahan yakni:

1. Implementasi Game Bahasa Model Uji Pengetahuan Untuk Meningkatkan Penguasaan Kosa Kata Bahasa Arab di Lembaga Pengembangan Bahasa Arab (LPBA) pondok pesantren Salafiyah Syafi'iyah Sukorejo Situbondo Jawa Timur

Di dalam kegiatan belajar-mengajar peranan penguasaan kosa kata bahasa Arab baik intrinsik maupun ekstrinsik sangat di perlukan. Dengan penguasaan kosa kata bahasa Arab, pelajar dapat mengembangkan aktivitas dan inisiatif, dapat mengarahkan dan memelihara ketekunan dalam melakukan kegiatan belajar.
Adapun implementasi yang dapat dilakukan di lembaga pengembangan bahasa Arab (LPBA) dengan cara melalui game bahasa model uji pengetahuan untuk meningkatkan penguasaan kosa kata bahasa Arab di lembaga pengembangan bahasa Arab (LPBA) pondok pesantren Salafiyah Syafi'iyah Sukorejo Situbondo Jawa Timur adalah sebagai berikut:

a. Pemberian tugas baik secara individu, teman sebangku maupun kelompok. Karena sudah menjadi kewajiban mu'allim untuk bisa menanamkan sikap positif pada diri anggota terhadap materi yang menjadi tanggung jawab dalam tugasnya.

b. Mengadakan Tanya jawab dan diskusi, sebab dalam kegiatan yang semacam ini anggota dapat terlibat aktif secara langsung. keterlibatan anggota secara aktif beraneka ragam bentuknya mulai dari memecahkan permasalahan yang ditanyakan sesama anggota, membandingkan satu konsep dengan konsep yang lain sampai menyimpulkan hasil diskusinya.di samping itu Tanya jawab sangat berguna mengenai materi pembahasan yang di sampaikan oleh mu'allim, pertanyaan yang baik yang kemudian dengan teknik pengajuan yang tepat akan membangkitkan minat dan rasa ingin tau anggota terhadap masalah yang sedang di bicarakan.

c. Menggunakan metode dan teknik mengajar yang di sukai anggota, agar anggota dapat survive dan tidak tegang, tidak menoton dan tidak merasa jenuh dalam kegiatan belajar mengajar.

d. Memberikan hukuman, hukuman disini akan ditimpakan kepada anggota yang melanggar peraturan atau tata tertib yang telah di tetapkan. Hukuman merupakan alat motivasi apabila di laksanakan dengan menggunakan pendekatan edukatif.

e. Memotivasi dengan kata-kata bijak, kegiatan ini akan mampu mendorong anggota untuk lebih bersemangat lagi 
dan cenderung akan menerapkan ungkapan-ungkapannya karena katakata bijak yang di sampaikan oleh orang-orang yang telah mengalami getir pahit-manisnya kehidupan lebih di yakini keberadaanya.

f. Memberikan peragaan. Untuk menumbuhkan semangat belajar anggota, seorang mu'allim di samping pinter dalam beretorika juga dapat memperagakan atau memperaktikan pelajarannya di hadapan anak didiknya. Hal ini sangat bermanfaat untuk di lakukan terutama dalam memudahkan pemahaman pengertian.

g. Memberikan pujian baik verbal maupun non verbal. Tujuan dari pujian tersebut agar anggota terpacu dan berusaha meningkatkan prestasi belajarnya. Dengan pujian yang diberikan akan lebih meningkatkan percaya diri anggota dan tentunya akan terus meningkatkan penguasaan kosa kata bahasa Arabnya.

h. Memberikan hadiah terhadap, hal ini dimaksudkan supaya ada kompetisi sehat antar anggota dan akan menguasai anggota dalam meningkatkan penguasaan kosa kata bahasa Arabnya.

Dalam implementasi meningkatkan penguasaan kosa kata bahasa Arab dapat dianalisis dengan pendapatnya Sardiman A.M. ${ }^{5}$. yaitu dapat dilakukan dengan cara (1) memberi angka (2) memberikan hadiah (3) adanya saingan (4) Egoinvolvement (5) memberi ulangan (6) megetahui hasil (7) hukuman (8) membangkitkan minat (9) memberikan pujian. Dari hasil lapangan dan tinjauan teori menunjukkan implementasi game bahasa model uji pengetahuan untuk meningkatkan penguasaan kosa kata bahasa Arab di antaranya adalah di sanah telah di terapkan game bahasa model uji pengetahuan oleh beberapa guru sedangkan untuk guru yang lain masih ada sebagian yang memakai yang

5 Sardiman A.M, interaksi dan motivasi belajar mengajar.Jakarta:CV Rajawali ,2011.hal.89 tradisional,pada mata pelajaran bahasa Arab seorang mu'allim harus mampu mencipta suasana pembelajaran yang efektif, yang memungkinkan anggota dapat mengikuti proses pembelajaran dengan baik sehingga mampu mempengaruhi peningkatan kosa kata bahasa Arab, dan juga dari analisis data dari pengamat peneliti menunjukkkan bahwa pembelajaran bahasa Arab hkususnya game bahasa model uji pengetahuan lebih menyenangkan dan anggota lebih aktif, hal itu di bandingkan dengan muallim yang mengajarkan mufradat yang memakai model tradisional.

2. faktor-faktor Pendukung dan Penghambat Game Bahasa Model Uji Pengatahuan Untuk Meningkatkan Penguasaan Kosa Kata Bahasa Arab di Lembaga Pengembangan Bahasa Arab (LPBA) Pondok Pesantren Salafiyah Syafiiyah Sukorejo Situbondo JawaTimur

Berdasarkan hasil obeservasi dan interview yang peneliti lakukan diperoleh data lapangan bahwa faktor-faktor yang dapat mempengaruhi penguasaan kosa kata bahasa Arab anggota LPBA dapat di klasifikasi menjadi dua macam yaitu:

a. Faktor Pendukung

1) Muallim kreatif dalam mengelolah proses pembelajaran, khususnya pembelajaran kosakata bahasa Arab.

2) Muallim rajin dan tekun dalam mengajar kosakata bahasa Arab.

3) Muallim bisa memotivasi para anggota LPBA untuk memperbanyak perbendaharaan kosakata bahasa Arab.

4) Situasi pembelajaran yang efektif dan kundusif, terutama ketika game bahasa model uji pengetahuan diterapkan di kelas.

5) Sarana prasarana yang lengkap dan memadai, sehingga penerapan game bahasa model uji pengetahuan dapat diterapkan secara efektif.

6) Adanya motivasi yang kuat dari sebagian besar anggota LPBA dalam mempelajari kosakata bahasa arab, guna mempermudah meraka 
dalam memahami kitab-kitab klasik yang di pondok pesantren Salafiyah Syafiiyah Sukorejo.

7) Game bahasa model uji pengetahuan ini sangat cocok diterapkan pada level mubtadi'in. karena rata-rata mereka masih senang dengan permainan.

b. Faktor Penghambat

1) Tidak semua muallim mengerti tentang teknik atau strategi pembelajaran bahasa Arab yang komunikatif dan interaktif, sebagaiman game bahasa model uji pengetahuan, akibatnya siswa merasa jenuh dalam proses pembelajaran.

2) Ada beberapa anggota LPBA yang kemampuan bahasa Arabnya di bawah rata-rata, sehingga penguasaan kosakata bahasa Arabnya pun kurang maksimal.

3) Game bahasa model uji pengetahuan ini tidak cocok diterapkan pada tingkat atau marhalah mutaqaddim.

4) Ada beberapa tempat atau kelas yang kurang memadai, sehingga kelas bahasa Arab tidak sesuai dengan standar, akibatnya penerapan game bahasa model uji pengetahuan dalam pembelajaran kosakata bahasa Arab sering tidak berjalan dengan maksimal.

5) Adanya beberapa siswa yang motivasinya kurang dalam mempelajari bahasa Arab, sehingga penguasaan kosakata bahasa Arabnya pun juga rendah. Dalam hal ini dapat dianalisis dengan pendapatnya Sardiman A.M ${ }^{6}$ kalau dilihat dari dasar pembentukannya motivasi adakalanya memang bersumber dari diri orang itu sendiri yang kemudian disebut dengan motivasi intrinsik dan yang jenis yang kedua adalah jenis motivasi ekstrinsik yaitu bentuk motivasi yang tumbuh karena di sebabkan

${ }^{6}$ Sardiman A.M, interaksi dan motivasi belajar mengajar.Jakarta:CV Rajawali, 2011.hal.9395. adanya rangsangan di luar dirinya atau lingkungannya.

6) Seringkali muallim kurang dalam memberikan contoh-contoh kalimat sederhana, untuk menunjang penguasaan kosakata bahasa Arab.

7) Kurangnya pelatihan pembelajaran bahasa Arab yang diadakan oleh LPBA bagi para muallim.

Dari data lapangan dengan menggunkan observasi dan interview sesuai dengan teori terkait bahwa kreatifitas mu'allim dalam menggunakan game bahasa model uji pengetahuan dalam pembelajaran merupakan model yang efektif dalam menyampaikan materi pembelajaran karena dapat mempengaruhi atau merangsang motivasi belajar anggota dan mampu menciptakan pembelajaran lebih kondusif dan menyenangkan lebih mudah untuk memahami pelajaran dan memotivasi peserta didik supaya lebih giat lagi untuk belajar, sehingga dapat meningkatkan penguasaan kosa kata bahasa Arab dan kualiatas belajarnya khususnya di lembaga pengembangan bahasa Arab (LPBA) pondok pesantren Salafiyah Syafi'iyah Sukorejo Situbondo Jawa Timur.

\section{Simpulan}

Berdasarkan hasil paparan data, dan pembahasan terhadap hasil temuan di lapangan maka dapat dikemukakan beberapa kesimpulan sebagai berikut:

1. Implementasi yang dilaksanan dengan cara memakai metode game bahasa uji pengetahuan untuk meningkatkan penguasaan kosakata bahasa Arab di lembaga pengembangan bahasa Arab (LPBA) Pondok Pesantren Salafiyah Syafi'iyah Sukorejo Situbondo Jawa Timur, dapat digambarkan sudah maksimal dan kompeten yaitu dengan melakukan beberapa kegiatan diantaranya: memberikan pengarahan dan bimbingan menciptakan kondisi pembelajaran yang kondusif, menstimulasi untuk menumbuhkan penguasaan kosakata bahasa Arab terhadap diri anggota, dan memberikan penghargaan kepada anggota 
yang memiliki kemampuan berprestasi. Dengan kegiatan tersebut, terjadi peningkatan penguasaan kosakata bahasa Arab yang cukup signifikan dalam proses pembelajaran bahasa Arab.

2. Adapun faktor-faktor yang dapat mempengaruhi terhadap penguasaan kosakata bahasa Arab di lembaga pengembangan bahasa arab (LPBA) Pondok Pesantren Salafiyah Syafi'iyah Sukorejo Situbondo Jawa Timur, di klarifikasi menjadi dua macam, yaitu adanya pengaruh yang bersumber dari dalam diri anggota yang kemudian di sebut faktor internal. dan faktor yang ke dua adalah faktor eksternal. seperti implementasi dukungan dan dorongan baik dari orang tua dan mu'allim serta wujudnya fasilitas yang menunjang terhadap aktifitas kelancaran proses pembelajaran.

\section{Daftar Pustaka}

Acep hermawan, M.Pdi, Metodologi sPembelajaran Bahasa Arab, (Jogjakarta : DIVA Press (Anggota IKAPI),2012)

Azhar Arsyad, Bahasa Arab dan Metode Pengajarannya, (Yogyakarta: Pustaka Pelajar,

cet.II, 2004)

Syamsuddin Asyrofi, et.al, Metodologi Pembelajaran Bahasa Arab, (Yogyakarta: Pokja

Akademik, 2006)

Djam'an satori, aan komariyah, metodologi penelitian kualitatif. (PT alfabeta, bandung )

Moh. Nazir, 2013, Metode Penelitian, (Ghalia Indonesia, Bogor)

Lexi J.Moleong, 2004, Metodologi Penelitian Kualitatif, (Bandung: Remaja Rosdakarya)

Nurul Zuriah, 2006, Metodologi Penelitian Sosial dan Pendidikan, (Jakarta: PT Bumi Aksara)

Sugiyono, 2011. Metode Penelitian Kuantitatif Kualitatif dan $R \& D$, (Bandung : Alfabeta, cv)
Abdul Hamid, et.al, Pembelajaran Bahasa Arab, (Malang: UIN-Malang Press, 2008)

Fathurrahman, Metode Imla, http://udhiexz.wordpress.com/2008/08 /08/metode-imladikte/,

M.khalilullah,S.Ag.MA media pembelajaran bahasa arab,(aswaja pressindo yogyakarta)

Tathul mujib , permainan edukatif pendukung pembelajaran, (teras Yogyakarta)

Drs. H. Tayar Yusuf \& Drs. Syaiful Anwar, metodologi pengajaran agama dan bahasa arab (PT Raja grafindo Persada, jakarta)

Imam Asrori,2009 aneka permainan penyegar pembelajaran bahasa arab (Surabaya Hilal Pustaka)

Syaiful mustofa strategi pembelajaran bahasa arab inovatif, (UIN maliki press)

Acep hermawan, metodologi pembelajaran bahasa arab. (Bandung remaja rosdakarya, 2011)

Ulin nuha, metodologi super efektif pembelajaran bahasa arab, (diva press Jogjakarta)

Wa muna, metodologi pembelajaran bahasa $a r a b$, (teras Yogyakarta)

Sardiman A.M, interaksi dan motivasi belajar mengajar.(Jakarta:CV Rajawali, 2011) 